Revistade
Economid
Contemporâned

\title{
O CAPITAL FICTÍCIO E CRISE ECONÔMICA: VISÕES PARA UM NOVO PARADIGMA*
}

\author{
Joanílio Rodolpho Teixeira ${ }^{a}$ \\ Paula Felix Ferreira ${ }^{b}$ \\ ${ }^{a}$ Universidade de Brasília (UnB). \\ 'Programa de Pós-Graduação da Universidad Autónoma de Madrid, Espanha.
}

Artigo recebido em 08/09/2014 e aceito em 24/08/2015.

\begin{abstract}
RESUMO: Este artigo tem o propósito inicial de conceituar o que é capital fictício e questionar seu papel na narrativa econômica ortodoxa. Outro objetivo é demonstrar os efeitos prejudiciais deste capital no Brasil. O capital fictício é toda rentabilidade proveniente da valoração derivada e artificial de um capital aplicado, já sem atuação na produção. Sua presença massiva sinaliza uma contradição interna no capitalismo atual, ainda que o pensamento convencional continue a se basear na crença de que crises econômicas são decorrentes de eventos exógenos e inesperados. A crise provém não de eventos aleatórios ou ao acaso, mas da dissociação entre circulação e produção, o que possibilita seu surgimento. Deste modo, a primeira parte deste artigo analisa a teoria do valor e do capital fictício como expressa por Marx e a heterodoxia; a segunda parte busca elucidar suas principais implicações para o caso brasileiro, e questiona a fé irrevogável que a ortodoxia tem na narrativa de crises supostamente surgidas de modelos de equilíbrio.
\end{abstract}

PALAVRAS-CHAVE: capital fictício; heterodoxia; crises; pensamento econômico.

CLASSIFICAÇÃO JEL: B50; G15; E10.

Correspondência para: Paula Felix.

E-mail: paulafelixf@gmail.com. 


\title{
FICTITIOUS CAPITAL AND ECONOMIC CRISIS: VISIONS TOWARDS A NEW PARADIGM
}

\begin{abstract}
This article has the purpose on defining fictitious capital theoretically and questioning its role on economic orthodox narratives. Its secondary goal is to demonstrate the harmful effects of such capital in Brazil. Fictitious capital is all rental obtained for the artificial and derivative valuation of invested capital without correspondence to production. Its massive presence signals an internal contradiction on current capitalism, even though conventional thinking still believes that crisis comes from exogenous and unexpected events. Actually, crisis occurs not by random but, indeed, through the dissociation between the circulationand the production process, which allows its offspring. The first part of this paper analyses basic aspects of the value theory and fictitious capital as expressed by Marx and the heterodoxy; the second part deals with the Brazilian case and questions the irrevocable 'Faith' that orthodoxy has on crises' narratives supposedly sprung from models of equilibrium.
\end{abstract}

KEYWORDS: fictitious capital; heterodoxy; crises; economical theory. 


\section{INTRODUÇÃO}

A economia mundial sofreu um grande abalo recente com a crise global de 2008 e até hoje amarga as suas consequências. Grande parte deste acontecimento pode ser remetida à emissão massiva de capital fictício, tema central do presente trabalho. Primeiro há de se determinar claramente o que é capital fictício e em seguida definir seu tipo de atuação nas economias doméstica e mundial.

De fato, o escopo de determinação do que é capital fictício é bastante amplo, porémnão as diretrizes gerais de sua natureza: é o capital que ulteriormente surge pela autonomia entre produção e circulação, e que oferece uma sustentação artificial dos lucros desassociada do uso de mão de obra. Este artigo dá continuidade ao esforço analítico realizado no grupo "Crescimento e Distribuição" do CNPq, em Brasília, do qual resultou o livro de Teixeira e Ferreira (2014), visando uma melhor compreensão das teorias heterodoxas.

A América Latina adentra a segunda década do século XXI em um contexto de dificuldade marcante nosconhecidos modelos de financiamento. Para o Brasil dos anos 1990, a abertura da conta capital serviu como um alívio para a fuga de capitais. No entanto, hoje a sua posição questionável quanto aos destinos globais do investimento externo direto (IED) traz à tona os fantasmas da instabilidade do sistema financeiro em face deuma estrutura produtiva macroeconômica moderna, mas ainda de natureza claramente emergente. Similarmente, os "abutres" (buitres) financeiros cobram da Argentina nova renegociação do calote dado há 13 anos.

Esta nova configuração dos países emergentes como agentes do seu próprio destino, mas ainda ancorados nas decisões tomadas no passado, não foi completamente escrutinada e exaurida por economistas desenvolvimentistas como Raúl Prebisch e Furtado. Assim, torna-se essencial questionar no contexto latino-americano os efeitos perversos da moeda sob o próprio olhar latino-americano, dada a estrutura produtiva em que a moeda aqui se apoia.

Frise-se ainda o lançamento do livro de Thomas Piketty (2014), O Capital no Século XXI, que também serviu de modelo e inspiração para este trabalho ao denunciar a crescente desigualdade de renda proporcionada no capitalismo. O estudo de Piketty tem gerado uma influência profunda no estudo da economia por denunciar novas descobertas sobre a desigualdade. Segundo o autor, estamos vivendo uma nova "Golden Age" (ou Era Dourada), em que a elite do 1\% possui um papel primordial na concentração de renda e na distribuição de riqueza em todos os estratos da sociedade. $\mathrm{E}$ mesmo que este papel fosse mais facilmente visível na elite aristocrática do século XIX, a elite atual se esforça em não aparecer nas estatísticas e na modelização matemática que busca entender a estrutura econômica contemporânea. Além desta injustificada 
tentativa de obscurecimento que Piketty denuncia, há ainda uma diferença muito mais atroz nesta nova elite: ela se enriquece majoritariamente por meio do capital fictício.

Além desta introdução, a segunda seção deste artigo consiste em trazer à luz uma melhor compreensão da teoria do valor-trabalho ricardiana e a terceira expõe as diferenças desta teoria em relaçãoà teoria do valor marxista. De posse dessas informações trazemos na quarta seção a conceituação do que é capital fictício, e na quinta indicamos sinais da sua presença no Brasil. As conclusões são apresentadas na seção final.

\section{A TEORIA DO VALOR-TRABALHO}

A teoria de valor-trabalho é uma análise econômica apresentada originalmente na obra de Adam Smith e David Ricardo e parte da visão de que a atividade econômica é essencialmente coletiva. No exemplo clássico, o valor econômico de uma mercadoria é dado pelo tempo de trabalho que é despendido no seu processo de produção; o trabalho seria o elemento fundamental que poderia conferir valor a uma mercadoria.

$\mathrm{O}$ fato de desconsiderar a matéria-prima e fazer do trabalho o fundamental componente do valor foi, ao longo da história, um bom legado a pensadores de diversas áreas. Entretanto, a questão da ontologia do valor permaneceu esquecida. No mundo clássico, o valor-trabalho e os preços de mercado se encontram em um estado de equilíbrio, no qual a moeda funciona como um intermediador imparcial e de efeito neutro. A principal dificuldade desse paradigma consiste, essencialmente, em sua influência no rearranjo dos preços ocasionados pela inflação.

A teoria tem sido elogiada frequentemente pela elegância e simplicidade ao estabelecer um modelo relativamente simples de convergência para o equilíbrio. Porém, muitas vezes a escolha de um modelo pode pecar pelo reducionismo. Sérias omissões podem ser encontradas na teoria do valor-trabalho, que, uma vez adicionadas, poderiam comprometer a estrutura do modelo. Com efeito, o ambiente de troca envolvido originalmente é elementar, onde prevalece a condição ceteris paribus ou mesmo uma economia de escambo. Contudo, como sabemos, o sistema de alocação de recursos é essencial para a determinação do sistema de mercado, bem como o seu período histórico. Se os sistemas podem ser de escambo, feudais, mercantilistas ou escravocratas, o processo capitalista torna a abordagem mais complexa. Ainda que nas sociedades pastoris bastasse a criação de gado para saciar a fome, nas economias e mercados capitalistas as relações contemporâneas para o estabelecimento do valor exigem o advento de indústrias, matadouros e canais de distribuição para a socialização do consumo. Do mesmo modo, a especialização da tecnologia exige cada vez menos horas de trabalho humano e muito mais uso de maquinaria. 
Ao se adicionar o componente histórico, o capitalismo oferece uma controvérsia essencial ao modelo: a entrada da moeda não como coadjuvante passivo, mas como ator principal em um sistema no qual a busca por dinheiro (e não a troca) impera. Outra disputa: se os preços são determinados pela lei de oferta e demanda, de modo que as utilidades marginais, no limite, vão reciprocamente se cancelando em decorrência da sua contraparte, tal apreciação é mera tautologia e nada explica sobre a gênese intrínseca do valor. E mesmo assim, Ricardo não se equivocou nos seus objetivos ao desconsiderar tais lacunas. $\mathrm{O}$ seu propósito sempre fora assumidamente declarado como uma teoria que determinasse quantitativamente a taxa de lucro, o que não deixa de ser um passo primordial para a compreensão da dinâmica do capitalismo.

Marx, por outro lado, sempre se interessou pela busca qualitativa do valor. A pergunta principal era como a essência do valor poderia ser determinada dentro de uma sociedade capitalista com distribuição desigual e regida pela lei do superlucro, não pela lei da concorrência perfeita. Ele chegou à conclusão que, no modo de produção capitalista, produção e circulação, bem como valor e preço, possuíam autonomia relativa, embora os dois estejam relacionados com a contradição privado-social ligada ao trabalho nas produções capitalistas ${ }^{1}$. A moeda seria o eixo central, a refletidora da divisão social do trabalho e o instrumento pelo qual a socialização dos trabalhos privados dentro da contradição privado-social é determinada. E como as trocas das mercadorias se realizam sob a norma dos preços de produção, uma forma de manifestação das crises seria por meio do capital fictício. Para chegar a tal dedução, foi elaborada a nova teoria do valor, desta vez não partindo de um modelo reducionista, mas sim da generalização dos processos privados e sociais em um momento específico da história (o capitalismo).

\section{FUNDAMENTOS DA TEORIA MARXISTA DO VALOR}

Marx determina o processo capitalista como formalmente nascido após o advento da Revolução Industrial, uma vez superado o processo de acumulação de capital denominado Acumulação Primitiva. Para muitos, a gênese do capitalismo continua aberta à discussão, especialmente para historiadores e cientistas políticos. No entanto, é justa-

\footnotetext{
Trata-se da contradição entre o trabalho realizado de forma privada, aparentemente independente dos demais, e a divisão do trabalho, que é social. A solução disso no sentido de que a economia funcione apesar da contradição se dá com a venda, porque a troca de mercadoria contendo trabalho privado converte-se em dinheiro, representante social do trabalho. Ou seja, o dinheiro é o validador social dos trabalhos privados contidos nas mercadorias e, por isso, tem enorme poder social.
} 
mente após o advento da indústria que muitos economistas políticos gostam de repousar seu campo de pesquisas, uma vez que este possibilita uma visão mais clara do processo de realocação de recursos desigual que engendrou a mais-valia.

O valor intrínseco de uma mercadoria pode ser visto como a cristalização de dois valores metodologicamente separados: o valor de uso e o valor de troca. Estes não devem ser vistos como entidades autônomas, mas sim como diferentes facetas que permitem enxergar um ente único.

O valor de uso trata não somente das propriedades funcionais de uma mercadoria mas também das satisfações que elas são capazes de proporcionar. Estas satisfações são numerosas, "quer provenham do estômago, quer provenham da fantasia" (Marx, O Capital, Vol. 1). Entretanto, em desacordo com a tese utilitarista, elas não são suficientes para se determinar o valor intrínseco de qualquer bem. Afinal, todos os bens também são submetidos ao valor de troca, alheio ao valor de uso, que permite a transação efetiva das mercadorias. O preço seria, neste aspecto, apenas o elemento material para a expressão do valor de uma mercadoria, mas não o seu valor intrínseco.

Portanto, não existe, tão somente, um conjunto de mercadorias que se regem pela oferta e demanda. Em princípio, todas as mercadorias estão submetidas à teoria do valor. Isto é, carregam um valor imanente em si, e este valor nada mais é que a representação social de como os recursos se realocam no capitalismo.

No modo de produção capitalista, o trabalhador deve alienar sua capacidade de trabalho (força de trabalho), vendê-la em troca de uma remuneração. Afinal, apenas tem isso para vender e precisa fazê-lo para comprar, porque o mundo capitalista é o de mercadorias. O capitalista, dono dos meios de produção, lhe oferece uma remuneração tal que permita um estilo de vida médio de cada sociedade, dependendo das condições históricas, o que é chamado por Marx de tempo socialmente necessário. Mas o trabalhador produz mais do que esse nível. No capitalismo o excedente é chamado de mais-valia e é o que excede o pagamento da força de trabalho, tendo como referência as condições médias socialmente necessárias.

Nesse contexto, o capitalista e o trabalhador lidam com diferentes condições: por um lado, o capitalista individual deve baixar o salário de seus empregados o máximo possível, do contrário incorreria em lucros e investimentos menores que os de seus concorrentes, tendo sua firma expulsa ou absorvida pelo mercado (em face da concentração e centralização de capital). Por outro lado, a classe dos capitalistas deve, em nível generalizado, fazer germinar um mínimo de renda necessário para a compra de suas mercadorias. Sem a efetiva venda destas, o valor produzido é nulo. Para que as mercadorias possam realizar-se enquanto valor, elas devem ser realizadas também na circulação, ou seja, devem ser vendidas. 
Maior contradição: o capitalista não se interessa fundamentalmente pelo bem que ele produz, desde que invista na firma e possa receber mais-valia na empreitada. Sob este status, o dinheiro é desejável pela capacidade de gerar maior valor, sendo, portanto, uma mercadoria, e a mercadoria mais desejável no sistema capitalista. Concomitantemente à promessa de gerar maior-valor, o dinheiro (preço) também funciona como o equivalente geral do valor. Vê-se que há uma autonomia relativa entre valor e preços.

É esta autonomia relativa entre produção e circulação (e entre preço e valor) que possibilita o advento de crises. Afinal, no sistema capitalista, o valor se torna o representante único de toda a relação social de produção e circulação de mercadorias, em uma sociedade que se divide tanto nas tarefas quanto na distribuição de seus produtos. Neste sistema, a moeda se torna o único meio para se chegar aos preços e é o único elemento que permite a superação da contradição privado-social por meio da socialização dos trabalhos via monetização, ou seja, monetarização das mercadorias.

No entanto, esta monetarização que permite a transação e a circulação das mercadorias em nível generalizado sofre diversos abalos no seu meio externo: estes abalos se dão pelo crédito, pela criação de dinheiro sem lastro na produçãoe pelas "fórmulas mágicas" em que um dinheiro investido pode gerar rentabilidade, sem o intermédio das mercadorias e da produção que socializa a divisão do trabalho e seu reflexo nas mercadorias.

\section{O CAPITAL FICTÍCIO}

Marx já fora crítico de Ricardo afirmando que não são tão somente as horas de trabalho concreto que explicam o valor, mas sim a efetivação de um trabalho generalizado, proveniente da validação dos trabalhos privados. Isto é, resolvendo a contradição privado-social por meio da venda de mercadorias no processo de circulação.

Uma função da moeda claramente perceptível é a possibilidade de separar no tempo as operações de compra e venda. Com o advento do capitalismo, a moeda também pode ser vista como capaz de gerar maior valor e, portanto, torna-se um bem desejável em si. No processo de abertura do crédito, o dinheiro emprestado possui a capacidade de sincronizar em um mesmo período de tempo a capacidade de produção de períodos de tempos distintos, o presente e o futuro. Por meio de uma carta de crédito uma firma pode potencializar no presente uma perspectiva de renda futura. Note-se, no entanto, que este empréstimo ratifica uma suposição de que a firma seria capaz de gerar tamanha competência em uma acumulação de capital futura que ainda não foi realizada no processo de circulação.

Perceba-se também que este crédito rende, periodicamente, uma cobrança de juros. Marx considerava que os juros não são decorrentes da oferta e demanda entre 
fornecedores e tomadores de empréstimos (como afirmam os economistas ortodoxos), mas sim que correspondem a uma antecipação de parte da mais-valia que o capitalista obteria caso fosse realizar sua empreitada somente com a acumulação de capital. Esta separação entre tempos possibilitada pelo crédito pode gerar dois resultados: i) a movimentação bem sucedida do capital em todas estas essas fases, o que não necessariamente implica equilíbrio dinâmico, ou ii) uma crise.

Um tipo especial de capital que pode produzir as crises é o capital fictício. Neste aspecto, tanto os escritos de Marx quanto o de pensadores posteriores (Harvey, 2006; Foley, 2005; Mollo, 2010 etc.) divergem sobre o seu significado.

Por um lado, é possível enxergar o capital fictício como todo capital que (à maneira do crédito) possui um valor $d u p l o$, um componente imaginário que não tem lastro na produção, mas pode vir a ter se for produtivamente aplicado. Neste âmbito, é possível considerar títulos do governo como capital fictício, uma vez que estes rendem juros a partir de uma dívida; isto é, o capital fictício torna seu portador mais rico a partir de um endividamento (falta imaginária de dinheiro), o que não tem correspondência no mundo real (Harvey, 2006).

Por outro lado, o capital fictício pode ser visto como uma valoração secundária e artificial de um capital aplicado que não tem lastro na produção. Nestes termos, o lançamento primário de uma ação está necessariamente atrelado ao valor de uso da firma correspondente, de modo que uma alteração significativa na firma (excessiva acumulação de capital ou vendas ruins com estocagem) afeta de modo paralelo o preço de suas ações. Mas o mercado financeiro não se resume a somente isso: geralmente, ativos são securitizados, lançados em portfólios de carteira com créditos derivativos e seus rendimentos gerados de forma aquém aos valores de uso de uma empresa, submetendo-se a maioria às leis de oferta e demanda especulativas por seus papéis.

Essa alteridade do modo de produção de uma empresa e a rentabilidade de seus ativos surge porque o advento do crédito possibilita a criação endógena de moeda sem que esta tenha lastro na produção. De fato, o detentor de tais ativos financeiros certamente será mais rico com o lucro gerado por seus papéis, mas no esquema de realização das mercadorias não há nova criação de produção suficiente para sustentar tal riqueza. Como o capital fictício também costuma apresentar uma rentabilidade maior e mais veloz do que o mercado produtivo, os lucros excedentes deste último tendem a ser reinvestidos no primeiro. A dissociação entre preços e valor se intensifica, ao passo que o mercado real de produção empobrece cada vez mais.

$\mathrm{O}$ advento do crédito permitiu aos bancos a criação endógena de moeda sem lastro na produção e abriu espaço para a possibilidade de crises. Aos poucos, o capital fictício passou a possuir poderes extremos - ele é capaz de criar, como um feitiço, dinheiro que se transforma em mais dinheiro, riqueza que engendra mais riqueza, em 
uma espiral descontrolada. No sistema capitalista clássico em que a busca pelo lucro rápido e acelerado é um imperativo para a sobrevivência, isto prejudica severamente a acumulação de capital e a circulação de mercadorias, tanto pela fuga de capitais quanto pelos efeitos diretos e indiretos que o mercado especulativo tem na produção. Mesmo assim, em médio prazo, a atratividade do capital fictício articula um grupo de seguidores poderosos que advogarão o livre trânsito do capital financeiro. Este suporte é concedido tanto pelas instituições governamentais, de elevado expertise econômico e baixo interesse na História, quanto pelos próprios economistas teóricos, que encontram na riqueza proporcionada pelo capital um forte argumento de manutenção das teorias ortodoxas.

Deste modo, reforça-se a mentalidade liberal trazida pela economia clássica, que já punha em voga o equilíbrio entre o câmbio e as balanças de pagamentos entre as nações sem dar a devida atenção às questões dos mercados internos. No entanto, o suposto equilíbrio atingido com a hegemonia da Pax Britannica foi reformado hoje para a livre circulação do capital fictício dentro da globalização.

\section{AS CRISES E A PRESENÇA DO CAPITAL FICTÍCIO NO BRASIL}

O crédito é um capital com valor duplo que possui lastro na produção e na circulação de mercadorias por meio da antecipação da mais-valia, de forma que todo seu montante é investido (ainda que em uma condensação do tempo) na produção. O capital fictício é (em nosso ver) a valoração secundária e artificial desse crédito, submetido a esquemas de especulação sem lastro na produção e cujo interesse central reside no contrato em si, não no objeto do contrato.

Nas últimas décadas, esse tipo de capital multiplicou-se vertiginosamente. Estima-se que em 2007, a renda gerada pelo mercado financeiro americano era dez vezes maior que o seu valor bruto adicionado na economia (Teixeira e Ferreira, 2014). Os Estados Unidos também acumulavam desde o início do século XXI consideráveis déficit na balança de pagamentos e elevado endividamento privado. No campo financeiro, os ventos iam bem: grandes firmas se utilizavam de swaps, securitização das dívidas, alavancagem e créditos derivativos. As nações capitalistas avançadas trabalharam consistentemente em conceder a livre movimentação do capital e a prescindir de qualquer regulamentação.

No Brasil, exemplos notórios de capital fictício podem ser trazidos à luz: com a alta taxa de juros destinada a atrair o capital estrangeiro, a dívida pública nunca é amortizada, prevalecendo tão somente o pagamento dos elevados juros. Afinal, tais títulos seriam lançados para saldar somente o serviço (juros) da dívida pública. Parece que o 
Brasil está se retroalimentando de capital fictício. Outra ocorrência similar foi a dos repasses de crédito do BNDES no período imediato pós-crise (notadamente, a grandes empresas) cujos fundos eram do próprio banco e de títulos do Tesouro. Contudo, para efetuar tal repasse o Tesouro Nacional vendeu títulos pagando taxas de juros de $10,75 \%$, enquanto as taxas de juros do empréstimo são equivalentes às de longo prazo (TJLP, na época 4,5\%). Essa diferença, de caráter alheio ao sistema produtivo, está sendo bancada pelos cofres federais.

A crise de 2008 também revelou como muitas empresas exportadoras no Brasil se mantinham ativas e lucrativas no período de sobrevalorização da moeda. Oreiro e Basílio (2008, p. 68) atribuem tal sobrevivência a fortes jogos especulativos das empresas de exportação que terminavam por cobrir os gastos operacionais deficitários das mesmas. Elas realizavam operações de target forward por meio de uma dupla aposta na apreciação cambial. Segundo os autores:

\begin{abstract}
Na primeira aposta, as empresas vendem dólar aos bancos por intermédio de um instrumento chamado forward. [...]. Uma operação clássica de venda de dólar no mercado a termo, apostando na apreciação cambial com o objetivo de ganhar os juros da operação. Outra possibilidade advém das operações de swap cambial reverso realizadas pelo $\mathrm{BC}$, operações que conferem às empresas cupom cambial no caso da queda do dólar.
\end{abstract}

Das duas operações resulta a de target forward: as empresas vendem novamente dólar para os bancos no mercado futuro, por intermédio da venda de opções de compra a descoberto, conferindo aos bancos o direito de comprar dólar a um preço préestabelecido. As empresas exportadoras compensavam perdas operacionais com ganhos financeiros, apostando que não haveria depreciação da moeda.

Dados estes exemplos, vemos que a livre assimilação do capital fictício aumenta a quantidade de riquezas presumidas, sem a possibilidade de realização no campo da circulação das mercadorias. Essa contradição interna somente se resolve com crises periódicas, quando o capital precisa se destruir pela realização de sua derradeira desvalorização.

O desencadear da crise se relaciona com o aumento da taxa de juros. Isso configura uma dificuldade de acesso ao crédito, mas rende maiores prêmios com o capital fictício quando a taxa de juros sobe. Nesse caso, o pagamento dos empréstimos contraídos antes fica difícil e as empresas precisam vender ativos para obter os recursos necessários ao pagamento dos empréstimos. Como muitas estão na mesma situação, a venda expandida dos ativos derruba os preços e piora a situação da firma que precisa vendê-los. Isso espalha a crise (Mollo, 2010). 
As colocações acima retratam o fato de as crises não serem, fundamentalmente, causadas por um fator exógeno de choque sob a subserviência do Estado, ou que iriam convergir a um ponto de equilíbrio conforme sugerido pela ortodoxia. Ao contrário, a relativa autonomia entre preços e valor e entre circulação e produção, possibilitada pela moeda e pelo crédito, sempre será uma fonte de instabilidade. Este é um conflito intrínseco ao capitalismo, que se resolve periodicamente com a ingerência de crises. Depressão e recessão são elementos tão comuns à realocação de recursos capitalistas como a moeda e a precificação. Infelizmente, tal resultado decorre de um perverso esquema no qual o capital fictício funciona sob a égide da privatização dos ganhos e socialização das perdas. Não houve, segundo afirma o discurso convencional, uma mera desregulamentação burocrática que "culminou” na inesperada explosão da crise. A crise constitui apenas um sintoma por meio do qual o capitalismo pode renascer e ainda se sustentar com todas suas contradições.

Paralelamente, já existe um aumento desgovernado de capital fictício ao redor do globo. Mollo (2010) estimou que no campo financeiro global esse valor já alcançou dez vezes a produção mundial. A existência do mercado de eurodólares torna o rastreamento desse capital ainda mais difícil e permite que ele flua livremente em mares internacionais onde as leis de regulamentação são mais flexíveis (Harvey, 2006).

A linha de pensamento econômico alternativa à convencional, representada por Marx, Luxemburg, Kalecki, Keynes, entre outros eminentes economistas heterodoxos, retorna ao debate econômico após a falha da ortodoxia em prever o grande distúrbio internacional iniciado em 2008. Essa linha de pensamento é crucial por revelar falhas intelectuais do modelo que permitiu o surgimento da crise recente. A visão heterodoxa é também importante por narrar contradições internas da economia capitalista, assim como sugerir medidas que, dentro de certos limites, podem contornar graves problemas de crescimento, distribuição e instabilidade do sistema econômico.

A narrativa do capital fictício e de sua apropriação teórica na convalescença da crise é similar ao relato trazido pelo historiador Marc Bloch no seu livro The Royal Touch: conta-se que na França acreditava-se que o rei tinha poderes divinos e que bastava ao soberano tocar um enfermo que este poderia ter curadas suas doenças de pele. Mas a questão principal consiste no fato de que esta crença, bem difundida, era baseada na ideia de um milagre: se o rei tocasse o doente e este não se curasse, é porque o milagre não havia acontecido. Após o doente ir várias vezes visitar o rei, se este se curava, era porque, naquela vez, o toque real havia funcionado. Fica a pergunta: será que, ao concedermos mais poder ao capital, mesmo sabendo da sua natureza explosiva e opressora, estamos esperando que este mesmo capital, em um ato súbito de benevolência, nos conceda um milagre? 


\section{REFERÊNCIAS}

BLOCH, M. The royal touch. New York: Dorset Press, 1989.

FOLEY, D. "Marx's Theory of Money in historical perspective”. In: MOSELEY F. (Ed.) Marx's theory of money -modern appraisals. Londres: Palgrave Macmillan, 2005.

HARVEY, D. The limits of capital. 6 ed. Londres: Editora Verso, 2006.

MOLLO, M. L. Credit, fictitious capital and financial crises: reviewing the antecedents of the current crisis. In: International Colloquium, Getting out of the Current Economics Crisis in the Light of Alternative Development Paradigms, 7, Annales, Paris, 2010.

OREIRO, J. L. C.; BASILIO, F. A. C. "A crise financeira brasileira: uma análise a partir do conceito de fragilidade à La Minsky”. In: ASSOCIAÇÃO KEYNESIANA BRASILEIRA (Org.) Dossiê da crise. Porto Alegre: AKB, 2008.

PIKETTY, T. O capital no século XXI. Rio de Janeiro: Ed. Intrínseca, 2014.

TEIXEIRA, J.; FERREIRA, P. A hegemonia do capital fictício: a crise global sob a perspectiva heterodoxa. 1 ed. Brasília; Curitiba: Editora CRV, 2014. 